\section{mat Northeast Center for Occupational Health and Safety Agriculture • Forestry • Fishing February 2018}

\section{What are our priorities?}

The Northeast Center for Occupational Health and Safety (NEC) is one of 11 agricultural education, research and prevention centers funded by the National Institute for Occupational Safety and Health (NIOSH). NEC partners with other $\mathrm{NIOSH}$ centers, state and federal agencies, land grant universities, medical centers, advocacy groups, and other not-for-profit organizations to carry out research, safety trainings, and intervention programs aimed at reducing occupational injuries and illnesses in agriculture, commercial fishing, and forestry (AFF) industries.

\section{What do we do?}

- Work with AFF communities, NIOSH and regional partners to:

Establish systems for tracking patterns of work-related exposures and injuries in AFF.

Develop and deliver bi-lingual prevention programs that increase access to safety technology and safety best practices.

Mobilize worker communities and industries to collaboratively address occupational health and safety hazards.

Develop, test, and disseminate engineering and evidence-based practice solutions.

Evaluate NEC research projects and programs.

- Collaborate with the Pennsylvania State University, the Johns Hopkins Bloomberg School of Public Health and the University of Massachusetts (UMASS)-Lowell on AFF research.

- Translate research findings into feasible and effective worksite practices and products.

- Implement the Rollover Protection System (ROPS) rebate programs nationwide by leading the National ROPS Rebate Program.

- Provide interactive worksite training opportunities for farmers and farm families, agricultural, commercial fishing and forestry workers, agricultural classes, agribusinesses, and occupational safety specialists.

\section{What have we accomplished?}

- Expanded the ROPS Rebate Programs into VT, $\mathrm{NH}, \mathrm{MA}, \mathrm{PA}, \mathrm{WI}$, and MN. Discussions with additional states are underway. ROPS continue to be installed in states with rebate funding and assistance locating ROPS is offered nationally through the National ROPS Rebate Program.

- Prevented tractor overturn injury deaths, with ROPS Rebate Program participants reporting 20 overturn incidents and close-calls.

- Improved injury surveillance of AFF workers, using electronic health data in $\mathrm{ME}, \mathrm{NH}, \mathrm{NJ}, \mathrm{CT}$, and MD. Piloted use of Bayesian methods to enhance free text searches to identify AFF injuries in these data.

- Conducted 2,965 educational farming and logging safety training sessions, from February 2012 through October 2017, training 37,695 workers and employers, by leveraging NIOSH and state-based funding sources.

- Conducted baseline surveys with NY farmers regarding Power Take-off (PTO) shield use before launching a 'Principles of Influence' campaign to increase the use and replacement of missing or broken PTO shields.

- Shared estimates of worker hazard exposures in the Northeastern lobster fishery with lobster fishermen. UMASS Lowell researchers are working with fishermen to develop easy and cost-effective prevention solutions for primary hazards contributing to fishing injuries.

- Allocated nine different personal flotation device (PFDs) designs to over 180 lobster fishermen to gather feedback on potential PFD design improvements to increase use.

\title{
What's next?
}

- Work with farming communities to mobilize interest in and increased use of PTO shielding.

- Disseminate improved ergonomic equipment designs with lobster fishermen.
- Establish baseline worker health status for a cohort of forestry workers in Maine.

- Increase lobster fishermen's readiness to use PFDs on a regular basis.

- Update cost-benefit analysis of ROPS.

\section{At-A-Glance}

The Northeast Center for Occupational Health and Safety (NEC) promotes health and safety research, education, and prevention activities in the high-risk areas of farming, commercial fishing, and logging from Maine to West Virginia. This snapshot shows recent accomplishments and upcoming work.

\section{NEC, located in Cooperstown, NY, serves 12} northeastern states

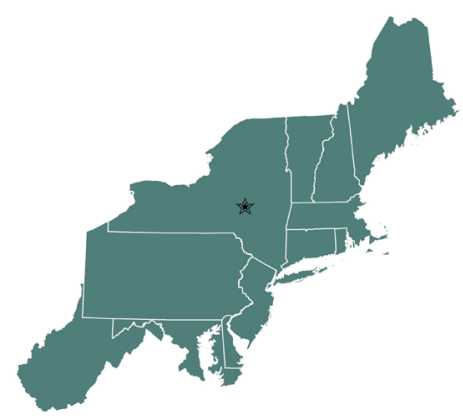

ROPS Retrofits (2,442)

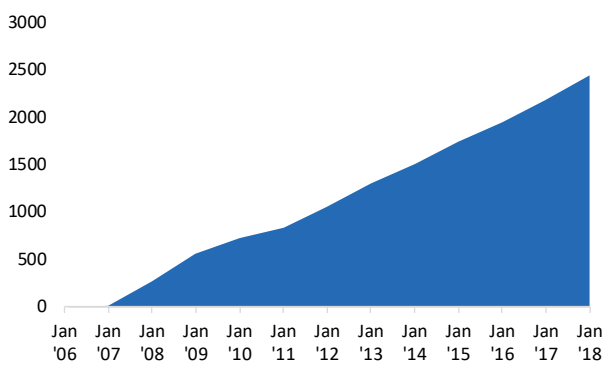

Source: National ROPS Rebate Hotline www.ropsr4u.com

\section{Number of Respiratory fit testing participants}

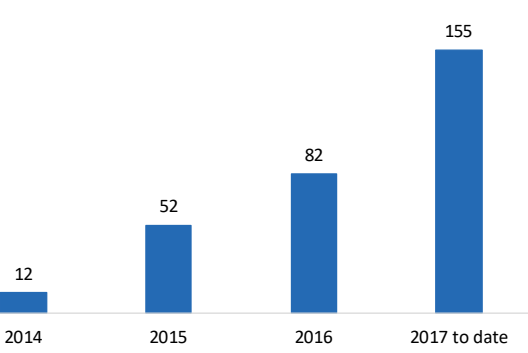

Source: NYCAMH HealthWorks www. bassetthealthworks.org

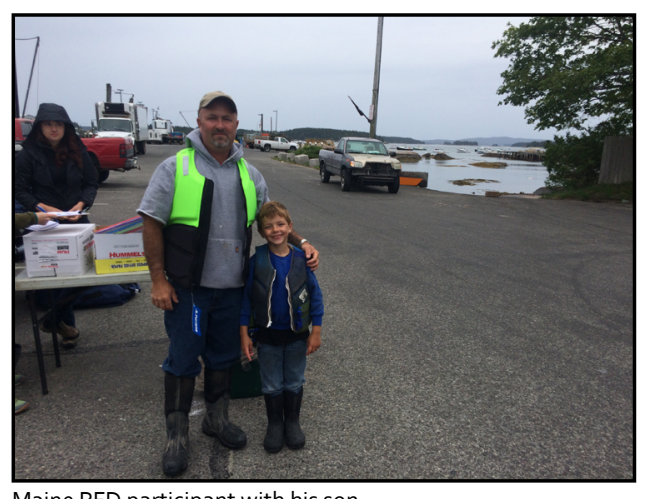

Maine PFD participant with his son 